\title{
BETWEEN PHILOSOPHY AND REALITY
}

\author{
PhD. Ramona Nicoleta ARIEŞAN, \\ Faculty of Philosophy and History, Babes-Bolyai University, Cluj-Napoca, \\ ROMANIA, \\ Email: cashmerephotography@gmail.com
}

\begin{abstract}
The main purpose of this scientific paper is to show the general importance of the fundamental knowledges about humanity, about what makes us human beings, about how reality interconnects with our dreams and desires. It might be hard living in a world where you feel suffocated by everything that is happening around you. It might be difficult to try and represent your own values and visions in a space where you are not allowed to stand out but you still feel the need to express who you really are. Immersing into your own world, becoming one with your mind and your body could help but at the same time it is not a real way of living because it cuts to the core every single connection that you, as a person, might have with this reality that you are living in. Not to mention the fact that it might not give you a real change to try and see just how everything that surrounds you responds to your thoughts and your actions and what you can learn from all those things that you are going through. I will try and expose some of these things, in an attempt to show how I have come to understand different perceptions, visions, morals and values and how my soul sees this reality. Also, I will try to explain different perspectives and why they are like that.
\end{abstract}

Keywords: Vision of life; reality between philosophy; perception; human being; paradox;

\section{INTRODUCTION. IMMERSING INTO THIS TRANSCENDING WORLD}

It all starts from various questions, perceptions and answers. The world, as we see it is filled with all sort of different things. But what are those exactly? How did they get to where they are right now? How was that process possible? Or maybe why wasn't it impossible? It is quite a difficult task trying to answer all these questions and many more regarding just these aspects. Some answers might be positive and others negative but in the end it all comes down to what we want to accept and how we can receive different information coming from different point of views and experiences. Not to mention the fact that there are far more questions to be asked and answers to be received.

"After thinking about what the world was made of, the ancient Greek philosophers questioned why there was a world at all. Why was there something, rather than nothing? Is it possible that something has always existed? We are so used to thinking of beginnings and endings that it is hard to imagine that something has always been there. On the other hand, could something such as the universe have been created from nothing?",

It might seem as an overwhelming amount of information. But knowing that we have to start somewhere, first and foremost, we will try to work with the assumption that indeed

\footnotetext{
1 Sarah Tomley, Marcus Weeks, Children's Book Of Philosophy. An introduction to the world's great thinkers and their big ideas, New York, DK Publishing, 2015, p.14
} 
there was something, that we had a foundation to build on and help us later down the road. Just like our life. We must exist in order to become someone. Even just the simplest person that has ever walked on this earth. But just our existence sometimes might not be enough. There will be times when we are going to need to prove something and in order to do so we must have at least a clear mind about who we started out as. Because as far as I am concerned, we cannot be sure of who we are going to be or where we will end up. Life, as we know it, is a motion filled with relative things. The abstract concepts are far away, maybe unreachable or maybe they are just waiting to be discovered.

You never know for a fact what is going to happen or how you are going to receive certain things. We can imagine different situations, we can picture ourselves in everything and everywhere, we can try and draw the reality that surrounds us but is all just a concept, just a vision or maybe just a dream. Reaching a point of no return might seem the most fitting destination. And I say this because being always between one general vision and your own personal one, a person might lose track of what is really going on in this dimension and he or she might get lost on this path of frenetically searching for the right way or maybe let's say the moral one. But this is a fight that is not suitable for a single person because life will eventually become overwhelming and things will hit rock bottom.

"If someone asked you "What exists?" you would probably point to the things around you and say "Everything!" If asked how you knew, you might answer that you can see, hear, touch, smell, or taste it all. But some philosophers think that it's not that simple. Our senses can be tricked and they might not tell the truth. Can we ever really know what's real?",

Sometimes our imagination can influence us in such a way that we no longer have the ability to distinguish between what is real and what is not. And it is all connected with that point of no return. But in other cases, our imagination might be just what we need, that little push that will help us move forward and stand our ground in the face of this world. The vision that some philosophers present to the world, the fact that things might not be as real as we believe they are, the fact that our sense can indeed be tricked will shift our visions, for the better, if we are willing to let that happen, to let our thoughts run alongside of our lives. I really believe the fact that we should bring a little color into this world in order to get a chance to see it as real and as naturally as possible as it unveils in front of us. Embrace it and live it to the fullest. Just let yourself lose all the rigors that have been induced since you first started your life in this world and in this culture and which gradually developed roots.

"We see the world in color-sky, trees, houses, animals, clothes, flowers, and everything else. But philosophers are not sure what color is or where it comes from, and some doubt that it is there at all. Is color part of the objects we see, or something that happens entirely in our minds? Is a lemon really yellow, or does it just seem yellow to us?",3

And these perceptions are generated exactly by the culture that we are born in and the visions and beliefs that we must embrace. Yes, colors might not exist. But if that is the case, then how can we tell apart things that have the same shape or the same smell or which are composed of the exact same materials? Everyone is entitled to an opinion. Just like you are and just like I am. And as far as I concerned colors do exist and are defined in a certain way, in such a manner that is a fact accepted on a general level and we are talking here about a worldwide phenomenon. Everywhere we go people are aware about the fact that there are

\footnotetext{
${ }^{2}$ Ibidem, p.24

${ }^{3}$ Ibidem, p. 28
} 
indeed different colors in this world and that although we call them by different names they are still the same.

And maybe the strongest argument which can be considered a pure fundament for this color existence debate is us, the human beings. We come in so many different color tones and shades that it would be almost impossible to affirm that is all just a vision of our minds. We have colors. But what we do not have as something guaranteed or as a general aspect is the way we perceive them. Some people are drawn towards a specific pallet of colors and others to different ones. We are not the same and this transcends to our perceptions.

Of course, we come from different parts of the world so the argument according to which we are not the same might seem a little bit of or a little bit weird. But our differences can also be applied to people that are coming from the same culture and have been raised in the same way. We inherit our national culture and maybe a small percentage of it will stay with us forever but we also take a lot of morals and values and ideas from the people surrounding us in particular but also from what we see that is not a part of our general cluster. Not only do we take everything in but we also start to analyze everything to compare ideas, visions, perceptions and to eventually come up with our own.

"Philosophers have always argued about what is real. Some believe that only ideas are real-these philosophers are known as Idealists. Realists say that only the objects around us are real. Another group of philosophers, the Pragmatists, believe that what matters is not the answer to "What is real?"-instead, what matters is what we believe to be real. They argue that what is true is what works."

It is often thought that creative minds are the one that can make the biggest difference. But is it always the case? I believe that it is indeed a very important aspect but I do not believe that is the most important one. Because, after all, this ability is not something that we can touch, at least not in the process. So, we might just say that it is not real. But at the same time, we cannot say that it is not real because we see the end result, we notice it and we can measure it (at least in most of the cases). Regardless, we prevail by saying that it is not necessary for a creative mind to always put out majestic ideas nor to deliver measurable results. ${ }^{5}$ Not all ideas become reality but this does not mean that they are not creative ideas. It just means that they were not made for this world or maybe for this period of time. Who knows? Maybe we had those ideas in another life, in another dimension or maybe in another world and they transcended time and space to reach this universe in which we exist. This could be seen as an out of body experience, but on a mind over matter perspective.

"Do you sometimes wonder which part of you is "you"? When you say or think "I," do you mean your body? Or, like the philosopher René Descartes, do you mean your mind, the "thinking" part of you? Maybe you agree with Descartes that mind and body are two separate things. On the other hand, you might feel like a mixture of both. Could there be a correct answer?" 6

Sometimes we might feel a strange sensation or go through a weird phase. And because it is something new to us, we do not really know how to treat it or how to respond to it. Also, we are often obliged to explain who we are or who we want to be, even though we have absolutely no idea how to put out an answer like that. It is not something difficult but something extremely difficult because it requires us to immerse into our own world and our

\footnotetext{
${ }^{4}$ Ibidem, p.30

${ }^{5}$ Heidegger M., Fiinţă şi timp, Humanitas, București, 2003, p. 209

${ }^{6}$ Sarah Tomley, Marcus Weeks, Children's Book Of Philosophy. An introduction to the world's great thinkers and their big ideas, New York, DK Publishing, 2015, p.42
} 
own soul and figure out who we are. But with that we might just give a certain answer which might lose its ground as time passes by because it is on rare occasions that we died the same person as the one people thought of us to be when we were born. We change. We become one, body and mind, or maybe we refuse to accept our bodies and we dream about having another one and we try everything in order for us to accomplish that dream. We cannot pinpoint the exact location as to where we are going to end up. But we can at least try to give everything that we have, to analyze every situation through different perspectives, just like philosophers do.

\section{WHAT MAKES PHILOSOPHY AN INTERESTING FIELD?}

"The modern era in philosophy, begun by Descartes, Bacon, and others in the seventeenth century, was based on a premise which has now become obsolete. The premise was that the very existence of knowledge was in question and that therefore the main task of the philosopher was to cope with the problem of skepticism. ",

In our day to day life we seem to hit a wall whenever we try to start a talk about certain aspects that are not so ongoing, to say the least. And it is quite an interesting experience because we are faced with all kind of people all with their own personal mind-set, perspectives, morals and values. And although we are filled with confidence and we are eager to hear what people have to say, we also encounter those who are completely against anyone who tries to start a movement on that specific topic or even just a small talk. So why is it just a strong feeling? Why is skepticism turning people into such small-minded individuals? Because it is, in some cases, the opinion sustained by the majority of the population and unfortunately it is very difficult to try and go against the majority.

"Why is philosophy always a double movement of destruction and recovery? Because, Heidegger contends, philosophy, as ontology, is fundamentally historical. The genuine pursuit of the question of being, the task of philosophy, is the same as the pursuit of the historical meaning of being." 8

And while trying to present our perceptions and trying to start a conversation on different topics we sometimes manage to understand where the people that are against us are coming from. And understanding their roots and their moral values we are able to form our speech in such a way that the message can be send across and over the wall that they have built. Basically, we get to know them as pure human beings and we get to know their core visions and thoughts. We go above and beyond the topic and reach a metamorphosis state in which everyone is able to comprehend the other's thoughts.

"If philosophy today has veered away from a fascination with the transcendent invisible toward critical examinations of social reality and linguistic practices, or toward searching dialogues with its own history, it has nonetheless left the historical articulations of the divide between the visible and invisible largely unexamined."

And that is the difference between what is real, what transcends our thoughts and what is just an idea, a vision, or maybe even a memory. We know the two parts of the matter but we have a hard time understanding the differences between them. We cannot define

\footnotetext{
${ }^{7}$ John R. Searle, Philosophy In A New Century. Selected Essays, New York: Cambridge University Press, 2008, p.4

${ }^{8}$ Walter A. Brogan, Heidegger and Aristotle. The Twofoldness of Being, Albany, State University of New York, 2005, p.7

${ }^{9}$ Véronique M.Fóti , Vision's Invisibles. Philosophical Explorations, Albany, State University of New York, 2003, p.2
} 
something that we cannot see or touch, something that is unreachable to our senses so we often run away from it. Maybe if we could run towards it, have a little more patience and understanding, allowing us to open up our minds we could reach new dimensions and we could make a lot more things become reality rather than just letting them pass us by.

It might seem as we are going against our selves in this matter but we are really just trying to obtain a higher level of understanding and seeing life. It is not enough to just picture something. We cannot enjoy it to the fullest if it remains just a vision when we could have made it a reality but we are too caught up in this day to day life to just let us become something more than what we are in the present moment. We need to learn that we have both a real and an imaginary part. We are not just made out of flash and bones. We have feeling, emotions, thoughts we have a lot of things that cannot be turned into something that we can touch. And that is alright. Actually, it is more than just alright. Because at the end of the day is this combination that makes us who we are. And at a certain level, our intangible part differentiate us amongst the others.

Yes, we are different, we have our own personalities, our own cultures, our own core values but as far as the tangible part is concerned we are still quite similar. Indeed, we can change who we are and we can become something else or someone else. But one thing is for sure: we will not be able to completely erase everything that ties us to our roots, to our cultures because those are the things that hold our essence. We have been completely immersed into our culture since the first moment that we had a life in this world. It is what we know for a fact and what we saw as real life examples.

"If one turns to Heraclitus as a thinker of vision, one finds that, far from understanding vision as a power of disclosing entities or qualities in their supposed selfidentity, he treats it as a power of originary differentiation. It reveals, in a privileged way, the pervasive incursion of alterity or disfiguration into customary identifications, as well as the counterplay of the granting and withdrawal of configurations of presencing." 10

It is quite amazing how we can change so many things with just a word or just a look. Yes, it has to happen at the right time, in the right moment with the right person but still, we are the one making the move, speaking up. We are the ones who are being different and proud of it because through this we are able to reach others in ways they could have not imagined. Not because they cannot, or because there is something wrong with them, but because they see the world like the majority, they see it as general aspect. And when we try to see it in a different color, when we start to analyze it, when we start asking ourselves why are we behaving in a certain way or how could we improve everything that is surrounding us, that is the moment when things actually start to gain motion and people shift thee attention towards us, the nonconformists, rather than keeping it in the same place. It might be hard to understand but we really need to focus more on what makes someone unique, on what vision they have, what are their dream and desires, and how they were able to reach the current perceptions and morals.

"The ontological structure of flesh is one of chiasmatic interconnections that cannot be collapsed into in-different unity. As already noted, one important way-stressed by Derrida, though ignored by Merleau-Ponty-in which vision attests to the elemental character offlesh is its proneness to be occluded by tears." 11

\footnotetext{
${ }^{10}$ Ibidem, p.3

${ }^{11}$ Ibidem, p.7
} 
The ways in which this life functions are quite an interesting aspect. You never really know what might happen nor how to respond to it. You never know what people might say or think. We could say that every aspect is like gambling with emotions. The future and what it holds will probably remain an enigma and a mystery for people in general. But if we look at this aspect from a certain point of view we might say that it is not such a bad thing after all. Because where there are mysteries there will always be people who will try to solve them and with this the circle of life will prevail.

"We are not observers who look at history from a distance; rather, insofar as we are historical creatures, we are always on the inside of the history that we are striving to comprehend." can be quite a consuming activity. And maybe this is the reason behind all those scandals that are happening in the world: the fact that we are constantly thinking about what the future is going to bring and the fact that we forget live in the present, in moment and take everything as it comes. The expression "we'll jump that bridge when we get there" holds a special part in everything that is going on but should be included a lot more because it should just become an anthem for our day to day lives.

Yet, neglecting all of the above we still have one more thing that could change the way we imagine and picture this life. Our feelings. Although we cannot define them as something reachable, they are there, present at any time given. And it is quite an interesting thing the way that they function. We fell more than be are able to express and we can share those emotions and form ties around them even without trying to do so. Life has a strange way of arranging everything and maybe that is the reason behind one of our most used expressions "everything happens for a reason". Maybe life is just a huge amount of feelings, tied together by people, by events, or by other emotions. And maybe this is the core to the human kind existence: we know how to share emotions together, we know how to use them in our advantage and when we do not know how to do that we can learn, either from others or from different parts of our existence and from what we have been through.

Trying to define how philosophy marks us and our lives is quite the time-consuming process because basically we are being surrounded by philosophy everywhere we look. It is indeed present in every aspect, in every time period, whether it is recognized or not, and we cannot always define it as we would want to.

It might be hard to exist in a world where trying to find answers to all sorts of questions might be something that is not allowed so easily but at the end of the day life is much more interesting when you have to overcome a challenge, when you have to put your mind to work, when you have to step out of your comfort zone and become who you really are or at least who you think you really are. At least for the time being.

\section{CONCLUSION}

Living in today's era might seem just like a paradox. You never know what is going on. You never know if what seems real is really like that or if it is just a mechanism that our mind uses in an attempt to cope with the cruel situation that we are face with. We cannot explain life just by using words. Many have tried and failed. Starting with the Greeks and the Romans, continuing with the entire history and not knowing when it will end. We can comprehend what we live in that moment and analyze it later. But it will not be the same. Just like all the differences that exist between what reality is and what we think it is, what I

${ }^{12}$ Hans-G. Gadamer, The Beginning Of Philosophy, New York, Continuum Publishing Company, 2001, p.29 
believe and someone else might and how all the factors influence the existing course of history.

There are always negative and positive parts. And it has always been like this and it will always be. Even Plato's ideas had supporters and haters. And not only did they pursue this scenario until our day to day life and it has made it possible for us to comprehend all the parts of this equation but they will continue to pursue this for a long time in the future. And we are talking here about the bond between people who participate in the same situation or at the same time or feel almost the same things. It is a bond that no one could ever break because it is based on feelings and perceptions. Everyone is situated in the same reality.

But that does not mean that we all feel the same or that philosophy marks us in the same way. It just means that we have a common space, we have something to share and to connect over. We are human beings and without communication, without feelings, without colors in our lives we would become machines. And that is the reality that we are running from. Yes, we have contradictions, yes, no one believes in exactly the same things but this is a crucial aspect because it enables us to become stronger together but also stronger as an individual.

\section{REFERENCES:}

[1] Brogan Walter A., Heidegger and Aristotle. The Twofoldness of Being, Albany, State University of New York, 2005

[2] Fóti Véronique M., Vision's Invisibles. Philosophical Explorations, Albany, State University of New York, 2003

[3] Searle John R., Philosophy In A New Century. Selected Essays, New York: Cambridge University Press, 2008

[4] Tomley Sarah, Weeks Marcus, Children's Book Of Philosophy. An introduction to the world's great thinkers and their big ideas, New York, DK Publishing, 2015

[5] Heidegger M., Fiinţă şi timp, (Being and Time), Humanitas, București, 2003

[6] Gadamer Hans-G., The Beginning Of Philosophy, New York, Continuum Publishing Company, 2001 